\title{
Systems Dynamics of Sheep Farms and Driving Herds of Faces to the Vagaries of Weather: Cases from the Region of El Bayadh
}

\author{
Mekhloufi Moulay Brahim ${ }^{1,2 *}$, Mahari Latifa ${ }^{3}$, Mekhloufi Fadila3 \\ ${ }^{1}$ Institute of Agronomy University of Mascara, Mascara, Algeria \\ ${ }^{2}$ Faculty of Sciences University Center of El bayadh, El bayadh, Algeria \\ ${ }^{3}$ Faculty of Science University El Djilali Liabès of Sidi Bel Abbès, Sidi Bel Abbes, Algeria \\ Email: agro752002@msn.com
}

Received 3 March 2014; revised 12 May 2014; accepted 29 May 2014

Copyright (C) 2014 by authors and Scientific Research Publishing Inc.

This work is licensed under the Creative Commons Attribution International License (CC BY).

http://creativecommons.org/licenses/by/4.0/

c) (i) Open Access

\section{Abstract}

The cattlemen of the steppe are faced with climate risks whose consequences are at the origin of one of the essential mechanisms of the degradation of resources natural fodder, thus making uncertain the food of livestock. Thus, faces to the changing socio-economic and climatic risks, the pastoral society has implemented different adaptive strategies to ensure the reproduction of its operating systems. The objective of this study is to analyze the patterns of the use of the space of the pastoral area called El-Bayadh in order to show how the actors adopt and adapt the techniques of production available in order to ensure the security of the production of their exploitation in an environment particularly fragile, hostile and vulnerable. It is therefore to take knowledge of the basic strategies implementation and the responses provided by the livestock producers to protect themselves against the consequences of a difficult climate in order to ensure the conduct of the food needs of their animals and the reproduction of their operating system.

\section{Keywords}

Breeding System, Conduct of Sheep Farming, Climate

\section{Introduction}

The pathways of arid regions are Algerian long exploited by mixed herds of small ruminants in difficult natural conditions. The evolution of society has led to the emergence of new modes of farming which come to substitute

*Corresponding author.

How to cite this paper: Brahim, M.M., et al. (2014) Systems Dynamics of Sheep Farms and Driving Herds of Faces to the Vagaries of Weather: Cases from the Region of El Bayadh. Agricultural Sciences, 5, 583-587. 
the nomadic. Livestock breeding is the first renewable resource. In effect, this economic activity represents a substantial share in the gross domestic product (GDP). However, the steppe in Algeria is the theater of a number of social transformations, economic and technical. These transformations occur in the aftermath of the breakdown of traditional balances between social groups and natural resources. The climatic factors are in part to the origin of this situation. In effect, the frequency of years of drought has increased considerably [1]. The availability of fodder sheep farmers has thus experienced a disturbing decrease. In this regard, the breeders are developing new strategies for breeding which cover very diverse forms (choice of species and breeds of animals, modes of conduct, management of stocks and the mobility of herds at the level of the socio-family economy, social organization, migration, etc).

In this context, the main question is: How these systems work for breeding and what are the basic strategies and the responses put in place by the cattlemen to protect themselves against the consequences of a difficult climate?

\section{Material and Methods}

The methodology used in our work is inspired by the systemic approach developed for a few years and which seems to be the best angle of study to better understand the operation of the systems for livestock farms [2]. This approach helps to explain the overall operation of a system by focusing on the study of the relations between the various elements. 06 Commons were chosen randomly within the region of El Bayadh (Figure 1). It is the commons of Brezina, Chellala, El Bayadh, Rogassa, Sidi Slimen and Bougtob located in frameworks geographic and socio economic different and which are deemed by the importance of the sheep farming. In addition, among these communes have already been the subject of studies by several agencies, which allows you to save time and facilitate understanding of the current dynamic of the livestock and the proposed solutions to the aridity of the climate.

Farmer survey is of the order of 32. These actors have been chosen randomly among the large, medium and small owners of livestock (Table 1). These breeders have been divided into 3 classes: Class 1: It represents the small farmers who possess a herd less than or equal to 50 head, Class 2: It brings together the actors intermediaries ente the classes 1 and 3 and which possess a herd which oscillates between 51 and 150 head, Class 3: It concerns the big ranchers having a flock of sheep important whose strength exceeds 151 heads (Figure 2).

\section{Results}

In the sample of study, there are actors who lead their flock modes in sedentary and migratory i.e. mobile, nomadic herding or semi nomadic herding (Table 2). The group of actors investigations gathers more cattlemen sedentary that of mobile pastoralists. It is rather the sedentary system which is the most dominant. It represents $38 \%$ compared to the whole of the investigations (Table 2).
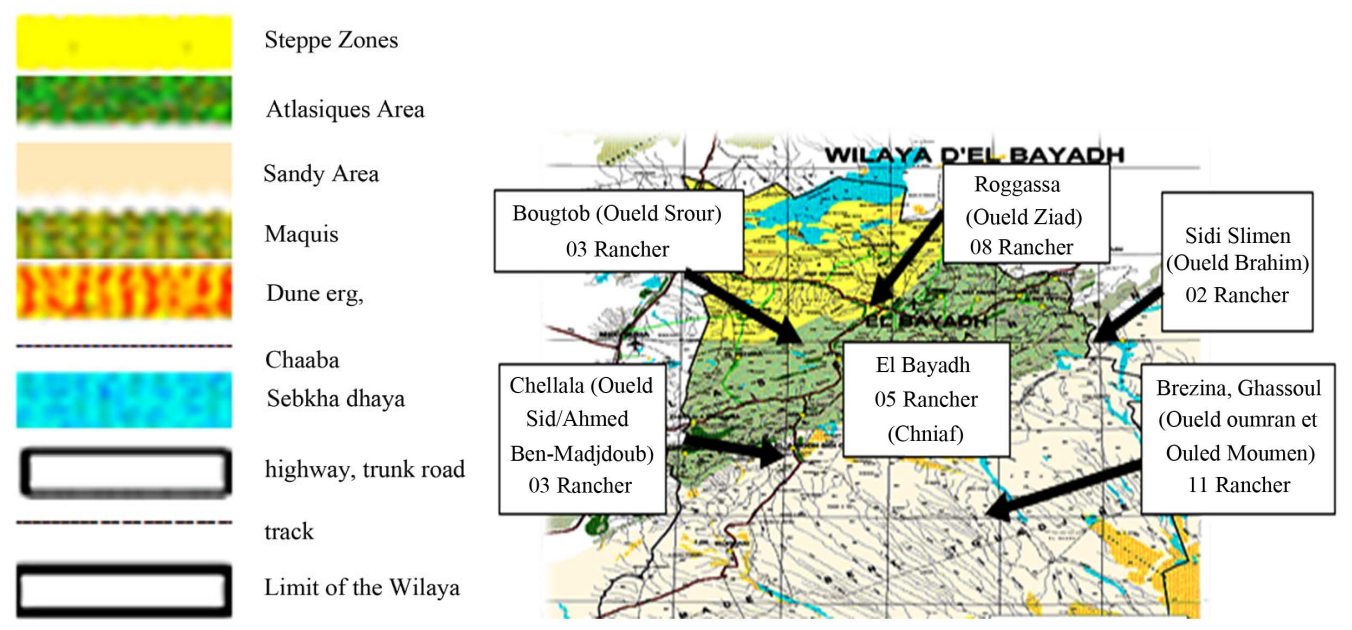

Figure 1. The framework of study (steppe environment: rainfall $<280 \mathrm{~mm} /$ year, region semi-arid has arid, vegetation degrade, soil undothed and poor). 
Table 1. Class of pastoralists investigations in the region of El-Bayadh (2006-2007).

\begin{tabular}{|c|c|c|}
\hline & Class of breeders & Cattlemen investigations in El Bayadh \\
\hline Small & & 4 \\
\hline Ways & & 8 \\
\hline Big & & 20 \\
\hline Total & & 32 \\
\hline
\end{tabular}

Table 2. Type of investigations in the region of study.

\begin{tabular}{ccccc}
\hline \multicolumn{4}{c}{ The region of study (El Bayadh) } \\
\hline Sedentary & Practicing transhumance & Semi practicing transhumance & Nomads & Total \\
\hline 12 & 09 & 08 & 03 & 32 \\
$38 \%$ & $28 \%$ & $25 \%$ & $9 \%$ & $100 \%$ \\
\hline
\end{tabular}

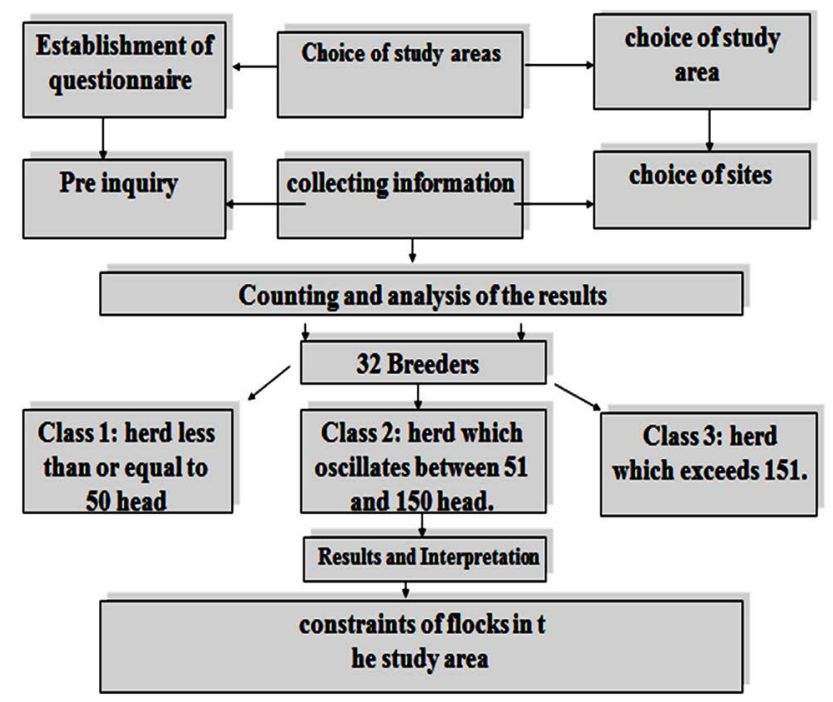

Figure 2. Methodological flowchart.

\section{Distribution of Classes of Surveys in Relation to the Criteria of Staff}

The size of herds is very variable and reflects a disparity between the ranchers investigations. Thus, on the basis of staff owned, three classes have been defined:

Class 1: less than 50 heads; Class 2: between 51-150 heads; Class 3: more than 151 heads.

The reading of the (Table 3 ) shows that 13 percent of livestock farmers hold investigations of small herds whose staff do not exceed 50 head, 25 percent have herds of ways in which the workforce is between 51 and 150 head and finally 62 percent of investigations are in possession of large herds either more than 151 heads. Thus, it seems that in our days the great herds are split into smaller units. This trend has developed since the war of liberation and appears to be accelerated since the independence by the gradual sedentarization of the population. The herds of medium size (51 - 150 heads) are spread over the three systems among the herders sedentary, semi practicing transhumance and practicing transhumance of the region of study. For these actors, the herd is a means of livelihood and not a capital to make profitable. The results of (Table 3) show that the nomadic herders have herds of more than 151 heads. This category concerns the small farmers who live mainly in the livestock and are often in delicate situations and threats of disappearance. The herds of large and medium size are concentrated among the mobile investigations in particular the semi practicing transhumance and practicing 
Table 3. Distribution of classes of investigations in relation to the systems of rearing in the region of study.

\begin{tabular}{cccccc}
\hline Livestock production systems & Sedentary & Practicing transhumance & Semi practicing transhumance & Nomads & $\%$ \\
\hline Less than 50 heads & 03 & 00 & 01 & 00 & $13 \%$ \\
Of 51 - 150 Heads & 05 & 01 & 02 & 00 & $25 \%$ \\
More thane 151 heads & 04 & 08 & 05 & 03 & $62 \%$ \\
\hline
\end{tabular}

transhumance. Their production strategy is primarily focused on the achievement of a profit of payback of the capital. On the other hand, it would seem that the more herds are large in size, the more the factor mobility is needed. The mobilities and the size of herds therefore seem to be important factors discriminated in our explanation.

\section{Discussion}

\subsection{Constraints of the Farms in the Steppe Zone}

Climate change, in the circumstances, the decrease in rainfall during the past three decades, would be for the farmers one of the main factors the origin of the regression of the pastoral potential thus causing an intense dependence vis-to-screw of the food of livestock purchased [3]. This approach of analysis concerns only a reduced sample of farms practicing livestock Sheep in a middle to components pastoral care and pastoral. However, despite the inadequacy of the Statistical basis on the one hand, and the difficulty related to the collection of information on the other hand, a few Lessons can be learned already to assess the sensitivity of the systems of rearing to the Transformation of production conditions The analysis of these systems has enabled us to collect the diversity of practices of conduct of herds to face various difficulties. This brings us to summarize the major structural constraints and functional which hamper the smooth functioning of these farms.

\section{The drought and its consequences in the light of these observations}

It seems that the cattlemen and the institutional have too strongly inclined to see in the droughts of the exceptional events that are repeated then that we should instead consider the drought as a structural element of this ecosystem which we cannot escape and which it must therefore adapt. However if the ecosystem is in phase of degradation, droughts are not the only ones responsible. Anthropogenic factors are at the center of this problem.

\section{A low-tech of eleveursune low-tech of cattlemen: Traditional techniques}

Overall, the techniques of conduct of herds are in most cases the cause of the low zootechnical performance and economic holdings of pastoral and agropastoral (high fmortalities of young animals, late term abortions... etc.). Practices such as the excessive collection of milk to the lambs, the complementation excessive and unbalanced are the mark of a technicality failed. Some stakeholders indicated that the products derived from these farms are not able to cover the expenses incurred because of these constraints.

\section{A problem of releveun problem of reading: A conflict of generation}

On the basis of the interviews conducted and of our observations, it appears that the children of farmers have a tendency to detach it from the pastoral society in opting for a way of life different from that of their ancestors. As well, it was found a disturbing exodus toward the cities causing problems of labor and raised the parental holdings. These difficulties led to this group of farmers to resort to the female labor or to a berger employee to ensure the conduct and maintenance of herds including the caretaking.

\subsection{Strategies and Behavior of Stock Farmers}

Among the strategies of the farmer, it there's those who aim at long-term to protect the system of climate risk well before the drought had not arrived (preventive actions) and those which are designed to short-term to adapt by dabbing and reducing the impact of the risk [4].

\subsubsection{Strategies with Short-Term Business: Options Aimed at Maintaining the Survival of the Herd} In function of the problem experienced, livestock producers are faced with making decisions. Among these options, some provide only a relative protection and have no compelling features of sustainability.

1) Purchase of food concentrate; 2) Mixture of food; 3) Procurement methods of the food concentrate; 4) 
Table 4. Short-term and long-term Strategies adopted by livestock producers in the region to study.

\begin{tabular}{lccccccccccccc}
\hline \multicolumn{1}{c}{ Strategies } & \multicolumn{1}{c}{ Short-termStrategies } \\
& AC & V & D & AA & G & LF & EV & EL.B & CI & CM & AF & MT & PC \\
\% Of Ranchers & 63 & 56 & 66 & 47 & 63 & 9 & 34 & 31 & 22 & 19 & 28 & 69 & 25 \\
\hline
\end{tabular}

Legends: AC: Purchase concentrated, V: Sale, D: Travel, Aa: Purchase of animals, G: caretaking, LF: Rental fodder, EV: vaginal Sponge, EL.B: breeding cattle, BELOW: Cereals in irrigated, CM: Culture market gardening, AF: Arboriculture Fruit, MT: Medium Transport, PC: Small trade.

Food Storage; 5) The use of rentals various; 6) The movements throughout the annee; 7) a system of mixed livestock; 8) Appeals to the new reproductive technologies: synchronization of Chaleur with injection of P.M.S.G. The increase of the dose of PMSG induces a frequency of higher ranges to 2 and to 3, which can have adverse consequences on the birth weight, the viability and growth of lambs [5].

\subsubsection{Business Strategies in the Long Term: The Preventive Measures}

In view of the conditions of livestock entirely dependent on the climatic conditions, the practice is that the cattlemen remain cautious and take preventive measures that give them a certain food safety well before the drought had not arrived. On the whole, it seems that the diversification of agricultural economic activity is the strategy adopted by the majority of investigations. In fact, the pluriactivity is the answer for this group of farmers (Table 4).

1) Development of pluriactivity; 2) The culture of the potato: a speculation lucrative; 3) The establishment of the arboriculture fruitiere; 4) The investment in the means of transport; 5) Increase of food autonomy and income additional years; 6) Modification of the composition of the herd; 7) Introduction of the cattle herd local level; 8) The use of off-farm income.

\section{Conclusions}

The steppe has had a strong development marked by an increase of the livestock and the rural population. The grazing resources have experienced a decrease due to the expansion of cultivation, the failures of agricultural policies and climate change (drought). This has made the pastoral farming much more fragile and vulnerable. In this context, the cattlemen have adopted a set of strategies (complementation, mobility, irrigation, etc.). The farmers with land appear better resist to the decapitalization. By contrast, the farmers without land are doomed to disappear.

This study has allowed to reveal that on the methodological level, the approach and the tools adopted have resulted in a better understanding of the strategies implemented in works by the cattlemen to meet the contingencies to maintain and reproduce their holdings. Thus, it appears essential to undertake a number of studies and researches tailored to the request. By order of priority, it will be necessary to consider: the creation of an Observatory Production System.

On the other hand, the need of the organization of the livestock industry is in cooperative association. These proposals can be achieved only by means of appropriate methodological and multidisciplinary teams.

\section{References}

[1] Le Houerou, H.N. (2005) Environmental Problems of the Livestock Development in Dry Region. Research Article Drought, 16, 89-96.

[2] Kanoun, M., Kanoun, A. and Ziki, B. (2006) The Products of Animal Husbandry Sheep Steppe. The Case of Djelfa Lambs. In: Olaizola, A., Boutonnet, J.P. and Bernués, A., Eds., Mediterranean Livestock Production: Uncertainties and Opportunities. CIHEAM/CITA/CITA, Zaragoza, 211-217.

[3] Kanoun, M. (1996) Income Structure of Agro Pastors and Effect of Production Techniques on the Formation of Income Common Case of Deldoul and El Guedid, Wilaya of Djelfa. Thesis of Magister, INA, Algiers, 124 p.

[4] Bourbouze, A. (2002) The Longtime of Development: Female Patients Transformation of the System of Farms in the Maghreb. In: Dufumier, M., Ed., An Agronomist in His Century, News of Rene Dumont, Khathala, Paris, 95-107.

[5] Poivey, J.P. (1988) Simple Methods of Calculated Values of Genetic Female Taking Account of All the Relatives. 18, 321-332. 